\title{
Stroke, multimorbidity and polypharmacy in a nationally representative sample of $1,424,378$ patients in Scotland: implications for treatment burden
}

Katie I Gallacher', G David Batty ${ }^{2,3}$, Gary McLean', Stewart W Mercer ${ }^{1}$, Bruce Guthrie ${ }^{4}$, Carl R May', Peter Langhorne ${ }^{6}$ and Frances S Mair ${ }^{*}$

\begin{abstract}
Background: The prevalence of multimorbidity (the presence of two or more long-term conditions) is rising internationally. Multimorbidity affects patients by increasing their burden of symptoms, but is also likely to increase the self-care demands, or treatment burden, that they experience. Treatment burden refers to the effort expended in operationalising treatments, navigating healthcare systems and managing relations with healthcare providers. This is an important problem for people with chronic illness such as stroke. Polypharmacy is an important marker of both multimorbidity and burden of treatment. In this study, we examined the prevalence of multimorbidity and polypharmacy in a large, nationally representative population of primary care patients with and without stroke, adjusting for age, sex and deprivation.
\end{abstract}

Methods: A cross-sectional study of 1,424,378 participants aged 18 years and over, from 314 primary care practices in Scotland that were known to be demographically representative of the Scottish adult population. Data included information on the presence of stroke and another 39 long-term conditions, plus prescriptions for regular medications.

Results: In total, 35,690 people (2.5\%) had a diagnosis of stroke. Of the 39 comorbidities examined, 35 were significantly more common in people with stroke. Of the people with a stroke, the proportion that had one or more additional morbidities present (94.2\%) was almost twice that in the control group (48\%) (odds ratio (OR) adjusted for age, sex and socioeconomic deprivation 5.18; 95\% confidence interval (CI) 4.95 to 5.43). In the stroke group, 12.6\% had a record of 11 or more repeat prescriptions compared with only $1.5 \%$ of the control group (OR adjusted for age, sex, deprivation and morbidity count 15.84; $95 \% \mathrm{Cl} 14.86$ to 16.88). Limitations include the use of data collected for clinical rather than research purposes, a lack of consensus in the literature on the definition of certain long-term conditions, and the absence of statistical weighting in the measurement of multimorbidity, although the latter was deemed suitable for descriptive analyses.

Conclusions: Multimorbidity and polypharmacy were strikingly more common in those with a diagnosis of stroke compared with those without. This has important implications for clinical guidelines and the design of health services.

\footnotetext{
*Correspondence: frances.mair@glasgow.ac.uk

${ }^{1}$ Institute of Health and Wellbeing, University of Glasgow, Glasgow G12 9LX, Scotland

Full list of author information is available at the end of the article
}

\section{Ciomed Central}

(C) 2014 Gallacher et al.; licensee BioMed Central Ltd. This is an Open Access article distributed under the terms of the Creative Commons Attribution License (http://creativecommons.org/licenses/by/4.0), which permits unrestricted use, distribution, and reproduction in any medium, provided the original work is properly credited. The Creative Commons Public Domain Dedication waiver (http://creativecommons.org/publicdomain/zero/1.0/) applies to the data made available in this article, unless otherwise stated. 


\section{Background}

Multimorbidity, defined as the presence of two or more long-term conditions, is becoming a global challenge for policy-makers, clinicians, and patients [1-3]. Treatment advances and increasing sub-specialisation of health services have improved functional outcomes for those with long-term conditions, but such changes have resulted in an increasing burden of treatment demands on patients, particularly those with multimorbidity [3,4]. Treatment burden is defined as the workload of healthcare for patients and the impact of this on their wellbeing [5]. It includes information gathering, attending multiple appointments, taking medications, enacting self-care, and, in countries that lack a health service that is free at the point of care, organising finances to pay for treatments [5-8]. There is a risk that patients become overburdened by their treatments, which can mean failure to adhere to management plans, thus resulting in ineffective treatment and wasted resources [3,9-11].

One aspect of treatment burden described above is polypharmacy, which can contribute to other treatment burdens such as adverse drug events [12,13]. Polypharmacy is most commonly defined as the use of multiple (usually five or ten) prescribed medications [14-16]. Although there is no strong evidence to support the use of any particular threshold, the risk of drug-related problems seems to increase with each additional medication prescribed $[17,18]$. There is a known association between number of morbidities and polypharmacy [19-21], with a study using routine Scottish health records finding that of those with two clinical conditions, $20.8 \%$ were receiving four to nine medications, and $1.1 \%$ were receiving ten or more medications; for patients with six or more comorbidities, these values were $47.7 \%$ and $41.7 \%$, respectively [19]. A systematic literature review investigating the relationship between the number of chronic conditions and healthcare utilisation outcomes found that about $60 \%$ of elderly respondents with zero or one condition reported taking prescription medications. This percentage went up to more than $90 \%$ for those with two or three conditions, and approached 100\% for those with more than five conditions [20], supporting the premise that those with higher numbers of conditions to manage are more likely to experience higher levels of treatment burden [3]. Other aspects of treatment burden such as healthcare utilisation have also been shown to be associated with multimorbidity $[20,22]$.

Stroke is a condition that can have a considerable impact on an individual's life. A recent systematic review of the qualitative literature revealed that people who have had a stroke experience four main areas of treatment burden: making sense of stroke management and planning care, interacting with others, enacting management strategies, and reflecting on management
[23]. Poor communication between patients and professionals was a common experience, exacerbated by fragmentation of health services and poor communication between healthcare providers themselves, aspects of stroke care likely to be exacerbated by multimorbidity [24-26]. Surprisingly, there has been limited exploration of multimorbidity or polypharmacy in people with stroke, the field being characterised by small-scale studies and a small number of conditions under examination [19,27-36]. Those studies that have examined stroke in relation to other longterm conditions have suggested that stroke is one of the diseases most significantly associated with polypharmacy $[19,33]$, but there is a lack of large-scale studies examining a broad range of medications and comorbidities.

In the current study, using a large, nationally representative cross-sectional primary care dataset, we examined the prevalence of multimorbidity and polypharmacy in people with and without stroke.

\section{Methods}

\section{Study design and participants}

This was a cross-sectional study based on a nationally representative dataset managed by the Primary Care Clinical Informatics Unit at the University of Aberdeen in Scotland. This fully anonymised dataset contains clinical data on all people that were alive and permanently registered with 314 primary care practices in Scotland on 31 March 2007. Comprising approximately one-third of the Scottish adult population, this sample has been shown to be representative of this population [37]. In the UK, registration with a medical practice is required for an individual to access National Health Service (NHS) healthcare in the community. It is estimated that over $98 \%$ of the population are registered with a medical practice [38], which systematically records information on each patient in an electronic medical record, for the purposes of registration and subsequent everyday medical care. We examined data extracted from medical records and collated for a previous study of multimorbidity that had examined the presence of forty conditions [1]. The NHS National Research Ethics Service approved the use of these data for research purposes. Patient consent was not deemed necessary due to full anonymisation of the data.

\section{Data collected and disease definition}

The data examined consisted of the following variables: sex, age, socioeconomic deprivation (measured from patients' postcodes using the Carstairs score [39]), counts of regularly prescribed medications and the presence of 40 long-term conditions, including stroke.

There is no 'gold standard' method for the measurement of multimorbidity, therefore the forty long-term conditions included had been chosen and defined based on a recent systematic review [40] and expert consensus 
[1]. Existing definitions for each long-term condition were used if possible, mainly those used in the Quality and Outcomes Framework (QOF) or by NHS Scotland $[1,41,42]$. If no standard definition was available, or there was concern about under-recording, then conditions were defined by the clinical members of the research team. For example, depression was defined as the presence of a QOF Read Code in the past year or receipt of four or more prescriptions for antidepressant drugs (excluding low-dose tricyclics, which are usually used for chronic pain) in the past year [1]. The definitions of all morbidities examined are given in supplementary material (see Additional file 1). Comorbidity was measured using a count of long-term conditions [43], with morbidities being noted as either mental health or physical morbidities. The original analysis measured the presence of a combined group of stroke or transient ischaemic attack (TIA), but for the purposes of this analysis, the presence of stroke alone was defined using the QOF Business Rules code set [41], and TIA was ignored.

As there are no standard definitions of regularly prescribed treatments or measure of polypharmacy, we utilised a count of current regular prescriptions, including tablets, inhalers, stoma care and topical therapies $[17,18]$. Regular ('repeat') prescriptions are clearly distinguished in UK general practice electronic medical records from one-off ('acute') prescriptions such as those for most antibiotics. For the purposes of this analysis, any regular prescription that was still active (that is, available for issue on request) on the date of extraction and that had been prescribed in the past 84 days was counted as current. This time frame was selected as this was the maximum length of a repeat prescription in Scotland at the time of data collection.

\section{Statistical analysis}

Analyses were predicated on a comparison of the characteristics of people with stroke (cases) and those without stroke (controls). First, the numbers of morbidities and prescribed medications in stroke cases and controls were calculated, and proportions within each group computed. Second, logistic regression, which produces ORs, was used to summarise the relationship between stroke and the presence of comorbidities and prescribed medications. ORs were initially unadjusted - for the purposes of comparison - then adjusted for the key confounding factors of age, sex and socioeconomic deprivation. Age and deprivation were used as continuous variables. Deprivation was measured using the Carstairs score, which is widely used in health research. The Carstairs score is based on four census indicators: low social class, lack of car ownership, overcrowding and male unemployment. The scores have been described as a measure that reflects access to 'those goods and services, resources and amenities and of a physical environment which are customary in society' [39]. The scores therefore cannot be described as a measure of the extent of an individual's material wellbeing, but are rather a summary measure applied to populations contained within small geographic localities. Further adjustment for number of morbidities was made when polypharmacy was the characteristic of interest. Associations between numbers of morbidities and prescriptions were assessed using Spearman correlation coefficients. For the purposes of this analysis, a $P<0.05$ was deemed statistically significant. All analyses were carried out using IBM Statistical Package for the Social Sciences (SPSS) Statistics software (V21).

\section{Results}

The analyses were based on 1,424,378 individuals (724,949 women) aged 18 years and over who were registered with a general practitioner. In total, 35,690 people $(2.5 \%)$ had a diagnosis of stroke. As anticipated, the mean age of people in the stroke group $(72.68 \pm 12.21)$ was higher than that of the controls $47.36 \pm 17.93)$. For the demographic characteristics for each group, see Additional file 2.

\section{Comorbidities}

Table 1 shows the number and percent of total morbidities, physical morbidities and mental health morbidities in the stroke and control groups, along with ORs for stroke in relation to these variables. Multimorbidity was common in stroke: of the study members with stroke, the percentage that had one or more additional morbidities present (94.2\%) was almost twice that in the control group (48\%) (OR adjusted for age, sex and deprivation 5.18; $95 \%$ CI 4.95 to 5.43). Disaggregating the data into type of morbidity revealed that physical morbidity was markedly more common in people with stroke (adjusted OR 4.50; 95\% CI 4.31 to 4.68), and mental health morbidity was also more common but the relationship was less strong (adjusted OR 2.10; 95\% CI 2.05 to 2.15). In terms of assessing whether these differences exist across different age groups, a sub-analysis for age groups 35-44 years and $75+$ years was performed (see Additional file 3). This indicated that differences were larger for the younger age group, and increased with the number of conditions (a similar picture was found for number of repeat prescriptions). However, the skewed distribution of stroke prevalence towards the oldest age groups make any assessment of differences by age problematic, owing to the small sample sizes in the youngest age groups.

The ten most frequent comorbidities present in people with a diagnosis of stroke were: hypertension (60.9\%), coronary heart disease (29.5\%), painful condition (21.9\%), depression (20.7\%), diabetes (18.8\%), chronic kidney disease (14.3\%), constipation (13.8\%), atrial fibrillation (13.0\%), thyroid disorders (11.9\%), and chronic obstructive pulmonary 
Table 1 Stroke status and number of morbidities $(N=1,424,378)$

\begin{tabular}{|c|c|c|c|c|}
\hline & $\begin{array}{l}\text { Stroke N (\%) } \\
35690(100)\end{array}$ & $\begin{array}{l}\text { No stroke (\%) } \\
1388688(100)\end{array}$ & $\begin{array}{l}\text { Unadjusted OR } \\
(95 \% \mathrm{Cl})^{\mathrm{a}}\end{array}$ & $\begin{array}{l}\text { Age, gender and } \\
\text { deprivation adjusted } \\
\text { OR }(95 \% \mathrm{Cl})^{\mathrm{a}}\end{array}$ \\
\hline \multicolumn{5}{|c|}{ Total number of morbidities ${ }^{b}$} \\
\hline None & $2053(5.8)$ & $721430(52.0)$ & 1 & 1 \\
\hline One-three & $17750(49.7)$ & $551295(39.7)$ & 11.31 (10.81 to 11.85$)$ & 4.35 (4.15 to 4.56$)$ \\
\hline Four-six & $12300(34.5)$ & $100500(7.2)$ & 43.01 (41.03 to 45.09$)$ & 8.59 (8.17 to 9.04$)$ \\
\hline Seven or more & $3587(10.1)$ & $15463(1.1)$ & 81.52 (77.04 to 86.26$)$ & 12.81 (12.05 to 13.61$)$ \\
\hline \multicolumn{5}{|c|}{ Number of physical morbidities ${ }^{b}$} \\
\hline None & $2769(7.8)$ & $800202(57.6)$ & 1 & 1 \\
\hline One-three & $20716(58.0)$ & $510846(36.8)$ & $11.72(11.26$ to 12.20$)$ & 4.03 (3.86 to 4.20$)$ \\
\hline Four-six & $10414(29.2)$ & 70709 (5.1) & 42.56 (40.79 to 44.41$)$ & 7.32 (6.99 to 7.67$)$ \\
\hline Seven or more & $1791(5.0)$ & $6931(0.5)$ & 74.68 (70.05 to 79.61$)$ & 10.33 (9.64 to 11.05$)$ \\
\hline \multicolumn{5}{|c|}{ Number of mental morbidities } \\
\hline None & $21961(61.5)$ & 1163095 (83.8) & 1 & 1 \\
\hline One-three & $13533(37.9)$ & $223739(16.1)$ & 3.20 (3.13 to 3.27$)$ & 2.08 (2.04 to 2.13 ) \\
\hline Four or more & $196(0.5)$ & $1854(0.1)$ & 5.60 (4.83 to 6.49$)$ & 3.56 (3.03 to 4.20$)$ \\
\hline
\end{tabular}

all $\mathrm{p}<0.001$.

bexcluding stroke.

disease (11.9\%). Prevalences of all morbidities are shown in supplementary material (see Additional files 4 and 5).

Figure 1 displays the ORs (adjusted for age, sex and deprivation) for stroke in relation to the thrity one physical morbidities examined. The supplementary material (see Additional file 4) elaborates on this by showing both the unadjusted and adjusted ORs along with the crude prevalence of all physical morbidities in the stroke and control groups. In all, twenty eight of the thirty one physical morbidities examined were significantly more common in the stroke group, this was twenty seven after adjustment for potential confounding factors. For instance, epilepsy (adjusted OR 4.43; 95\% CI 4.14 to 4.74), hypertension (adjusted OR 2.67; 95\% CI 2.61 to 2.73 ), peripheral vascular disease (adjusted OR 2.47; 95\% CI 2.37 to 2.58), AF (adjusted OR 2.44; 95\% CI 2.36 to 2.53 ) and CHD (adjusted OR 2.06; 95\% CI 2.01 to 2.11) were all more common in people experiencing a cerebrovascular disease event. By contrast, dyspepsia was markedly less common in the stroke group (adjusted OR 0.63; 95\% CI 0.60 to 0.66 ). Figure 2 shows the ORs (adjusted for age, sex and deprivation) for stroke in relation to eight mental health morbidities. The unadjusted and adjusted ORs, along with the crude prevalence of all mental health morbidities in the stroke and stroke-free groups, are shown in supplementary material (see Additional file 5). In all, six of the eight mental health morbidities examined were significantly more common in the stroke group, and following adjustments, all eight mental health morbidities were significantly more common. These included drug and medication use problems (adjusted OR 2.34; 95\% CI 2.25 to 2.43), depression (adjusted OR 2.09; 95\% CI 2.03 to 2.15), alcohol problems (adjusted OR 2.05; 95\% CI 1.96 to 2.15 ) and anxiety and stress (adjusted OR 1.61; 95\% CI 1.55 to 1.66).

\section{Regular prescriptions}

As anticipated, the number of regular prescriptions was significantly correlated with number of morbidities in the stroke (Spearman's $\rho=0.58 P<0.001$ ) and control (Spearman's $\rho=0.75 P<0.001$ ) groups. Table 2 shows the number of repeat prescriptions in the stroke and control groups, and the ORs. Those with stroke were more likely than the controls to be on a repeat prescription (adjusted OR 4.53; 95\% CI 4.33 to 4.74). In the stroke group, $12.6 \%$ had eleven or more repeat prescriptions compared with only $1.5 \%$ of the control group (OR adjusted for age, sex, deprivation and morbidity count 15.84; $95 \%$ CI 14.86 to 16.88$)$.

\section{Discussion}

\section{Summary of findings and implications}

Analyses of a large, nationally representative sample of people in Scotland, a country with universal healthcare, showed that multimorbidity and polypharmacy were more common in people with a diagnosis of stroke. These findings are consistent with our knowledge that those with stroke are an elderly population with considerable cardiovascular disease risk [44], for whom effective treatments are increasingly available to alleviate symptoms and address underlying causal factors [45]. Diagnoses of most chronic conditions were more common in the stroke group, and this remained the case 


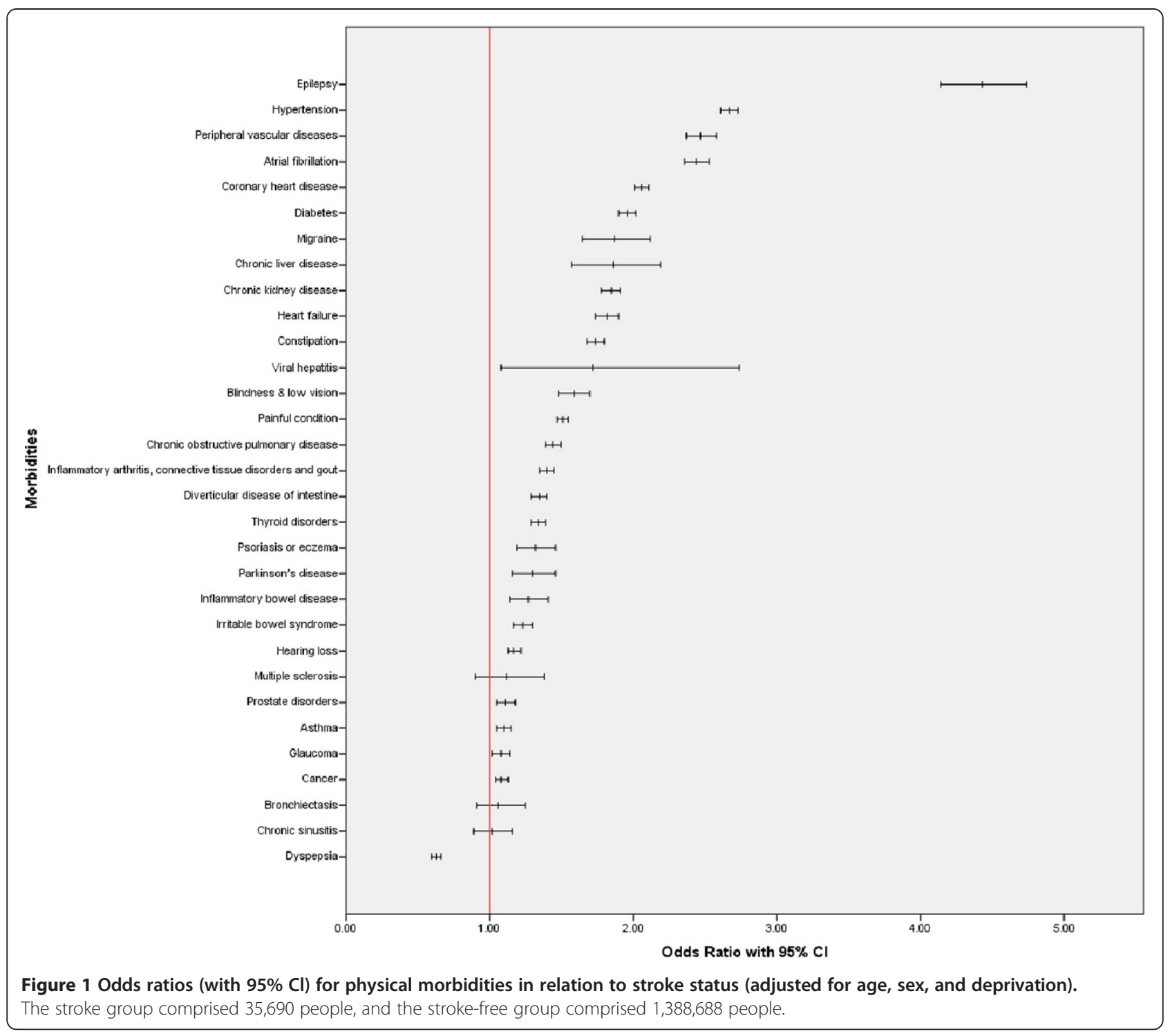

after adjustment for age, sex and deprivation. In our preliminary analyses (see Additional file 2), both age and deprivation were associated with stroke in the expected directions. This gives us confidence in the novel results presented herein.

Polypharmacy represents only one aspect of treatment burden, but is directly measurable, and may be a proxy measure of wider aspects of burden [17,18]. Multimorbidity is likely to increase treatment burden in several ways. First, as this study and others have shown, the number of medications increases with number of conditions [20,21]. Second, treatments may interact, leading to side effects $[5,7,46]$ and this has the potential to further increase the volume of work; for example, as new treatments are given to compensate for interactions [47]. Third, multimorbidity is likely to increase healthcare contacts and affect the capacity of the individual to follow therapeutic regimens [48]; for example, those with stroke and comorbid arthritis may find physiotherapy sessions more challenging $[49,50]$. Fourth, multimorbid patients who become overburdened, for example by complex medication regimens, may be less likely to adhere to therapies, leading to poor disease control and a further escalation of treatments by health professionals, further increasing treatment burden [3,9,51]. While many pharmacological therapies may be beneficial for those with stroke, a key question is whether people with stroke have made informed decisions regarding whether or not to take so many medications, given their modest benefits. Although perceived treatment burden and capacity to cope with any given treatment burden will vary, we would recommend that patients with stroke are made aware of the relative benefits of their drugs, and are empowered to make their own decision whether to take them. 


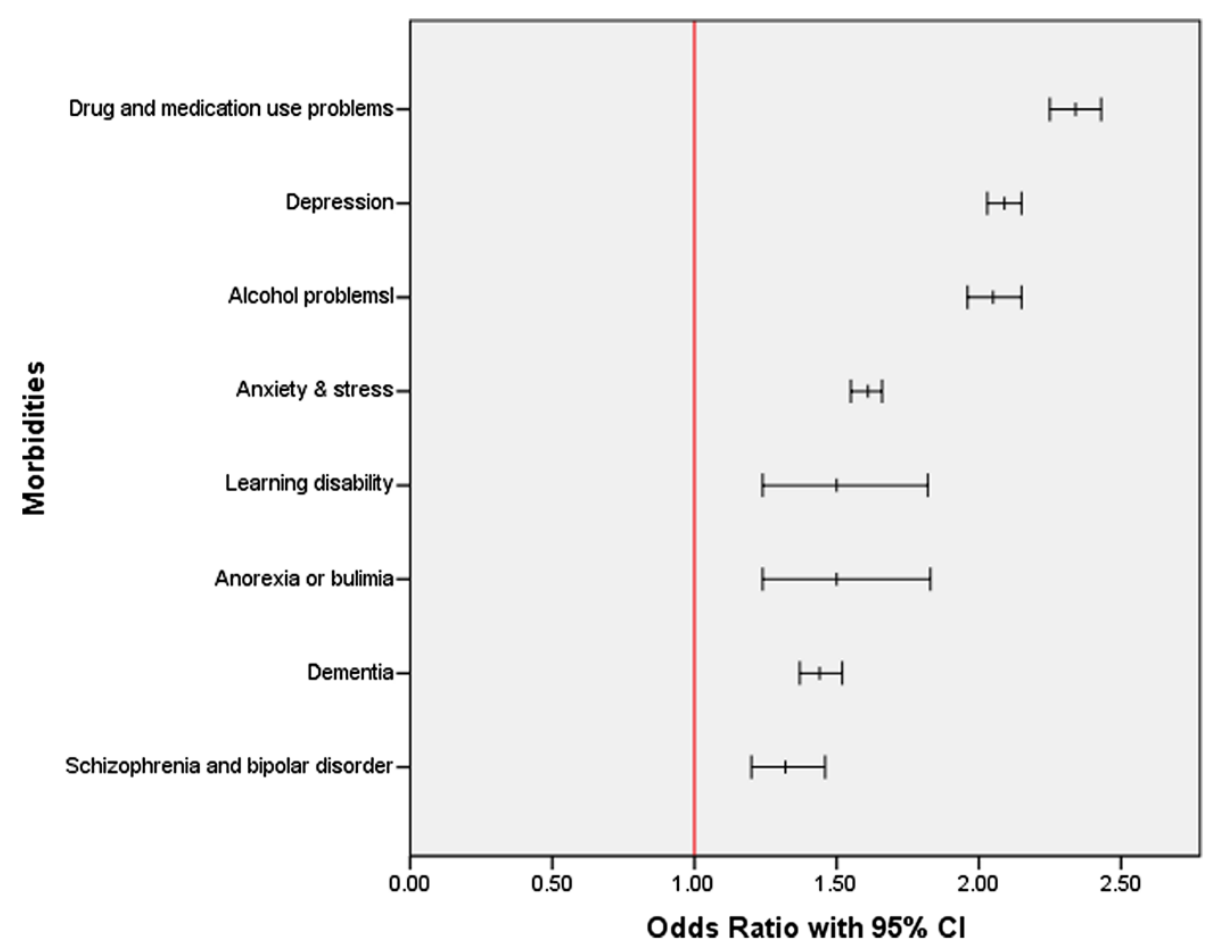

Figure 2 Odds ratios (with $95 \% \mathrm{Cl}$ ) for mental health morbidities in relation to stroke status (adjusted for age, sex, and deprivation). The stroke group comprised 35,690 people, and the stroke-free group comprised 1,388,688 people. Note: Drug related problems is any Read code which records psychoactive substance abuse which includes both drug misuse and prescription drug problems of multiple sources.

Acknowledging and addressing treatment burden in stroke, particularly for those with multimorbidity, may improve the patient experience, adherence to therapies, and health outcomes [48]. Minimising unnecessary treatments, improving co-coordination of services and making care more patient-centred [23] are likely to lessen treatment burden, but will necessitate changes from policy level down to the individual consultation $[3,48,52,53]$. Most stroke management guidelines fail to mention multimorbidity, or merely acknowledge the more common comorbidities briefly with a lack of practical advice for clinicians [45,54-57]. We found only one stroke guideline that acknowledged the issue of polypharmacy, and again, detailed practical help was lacking [56]. This issue has been gaining prominence [58,59]. Guidelines should be redesigned to take account of comorbidity and treatment burden; for example, by providing guidance on potential interactions from drug combinations commonly prescribed for those with stroke and multimorbidity and how to deal with the possible side effects or interactions that may arise [47]. In the current study, $21.9 \%$ of people with stroke had a painful condition, $20.7 \%$ had depression and $13.0 \%$ had atrial fibrillation, increasing the risk of being prescribed non-steroidal anti-infammatory drugs (NSAIDs),

Table 2 Stroke status and number of repeat medications $(\mathrm{N}=1,424,378)$

\begin{tabular}{|c|c|c|c|c|c|}
\hline & \multirow{2}{*}{$\begin{array}{l}\text { Stroke N (\%) } \\
35690(100)\end{array}$} & \multirow{2}{*}{$\begin{array}{l}\text { No stroke N (\%) } \\
1388688(100)\end{array}$} & \multirow{2}{*}{$\begin{array}{l}\text { Unadjusted OR } \\
(95 \% \mathrm{Cl})^{a}\end{array}$} & \multirow{2}{*}{$\begin{array}{l}\text { Age, gender and } \\
\text { deprivation adjusted } \\
\text { OR }(95 \% \mathrm{CI})^{\mathrm{a}}\end{array}$} & \multirow{2}{*}{$\begin{array}{l}\text { Age, gender, deprivation } \\
\text { and morbidity count } \\
\text { adjusted OR }(95 \% \mathrm{CI})^{\mathrm{a}}\end{array}$} \\
\hline & & & & & \\
\hline \multicolumn{6}{|c|}{ Number of medications } \\
\hline None & $2447(6.9 \%)$ & 863688 (62.2\%) & 1 & 1 & 1 \\
\hline One-two & $3038(8.5 \%)$ & $240721(17.3 \%)$ & 4.45 (4.22 to 4.70$)$ & 2.38 (2.26 to 2.52$)$ & 2.29 (2.17 to 2.42$)$ \\
\hline Three-four & $6566(18.4 \%)$ & $122518(8.8 \%)$ & 18.92 (18.05 to 19.82$)$ & $6.25(5.95$ to 6.57$)$ & 5.78 (5.49 to 6.08$)$ \\
\hline Five-six & 8185 (22.9\%) & $75512(5.4 \%)$ & 38.26 (36.55 to 40.05$)$ & 10.50 (9.99 to 11.03$)$ & 9.36 (8.89 to 9.86$)$ \\
\hline Seven-eight & $6721(18.8 \%)$ & $43344(3.1 \%)$ & 54.73 (52.20 to 57.38$)$ & 13.90 (13.20 to 14.63$)$ & 11.94 (11.29 to 12.62) \\
\hline Nine-ten & 4219 (11.8\%) & $22536(1.6 \%)$ & 66.08 (62.76 to 69.57$)$ & $16.22(15.34$ to 17.15$)$ & 13.44 (12.65 to 14.29$)$ \\
\hline Eleven or more & $4514(12.6 \%)$ & $20369(1.5 \%)$ & 78.22 (74.32 to 82.32$)$ & 20.13 (19.05 to 21.27 ) & 15.84 (14.86 to 16.88$)$ \\
\hline
\end{tabular}

all $p<0.001$. 
anti-depressants, anti-platelet therapies and anti-coagulants concomitantly, which increases risk of adverse events, such as bleeding. Care pathways should be structured around the patient themselves, rather than the individual conditions, using a more generalist approach that considers issues such as multimorbidity as well as the individual's support network and financial resources $[9,60,61]$.

\section{Strengths and limitations}

This analysis was undertaken using data from a large, nationally representative, primary care sample, and as far as we are aware, this is the first study on such a scale to examine multimorbidity and polypharmacy in stroke. This sample is representative of the Scottish population [37]; however, it may not reflect experience in other countries and healthcare systems. The prevalence of stroke in this sample was similar to that shown in other studies $[44,62]$, further validating the data; however, the data were collected for clinical rather than research purposes. No standard methods for measuring multimorbidity or polypharmacy exist, therefore a pragmatic approach was taken. We examined thirty nine long-term conditions, which is substantially more than in previous studies. The rationale for including the conditions examined and the rules for identifying the presence of each were described in detail by the team who previously collated the data [1]. In addition, any medications bought over the counter or given from secondary care were not included. However, at the time of the analysis, prescriptions to people over sixty five years of age and to many people with chronic conditions were all free, with others being able to cap their out-of-pocket costs, thus suggesting a financial incentive to obtain medication via the primary care practice.

As this is a cross-sectional study, the data we have were taken from one particular point in time, and therefore no conclusions about temporality or causation can be made. The measure of comorbidity was unweighted, as the aim was to be descriptive rather than to assess outcomes. This was deemed to be the most appropriate method, and is similar to that used by others investigating the prevalence of multimorbidity [1], but could be viewed as a limitation, especially as there may be a qualitative difference between the effects on perceived treatment burden of long-term conditions that produce regular symptoms (for example, heart failure) and those that are asymptomatic (for example, hypertension). We have no information about stroke severity, which is also a potential limitation. It should also be noted that due to the nature of the study, multiple analyses were carried out. Thus, the large numbers of cases and controls assessed in this study may have identified some associations that were statistically significant but not necessarily clinically significant; for example, for conditions such as cancer, glaucoma and asthma, which had ORs between 1.08 and 1.10 but were statistically significant with $P<0.001$.

Lastly, to explore treatment burden in stroke, this study examined multimorbidity and polypharmacy, however there are many more aspects of treatment burden still to be examined, such as clinic visits, continuity, coordination of care, and financial burden of therapies. The development of a patient-reported measure would enable a more detailed examination of treatment burden in stroke from the patient perspective.

\section{Conclusion}

In this study, we found that multimorbidity and polypharmacy were strikingly more common in those with stroke than those without. Polypharmacy can be thought of as a direct measure of one aspect of treatment burden, and we would suggest that people with stroke should be made aware of the relative benefits of their drugs so they can make informed decisions about therapeutic regimens. Both polypharmacy and multimorbidity are likely to be proxy markers for other aspects of treatment burden, as patients face the demands of managing multiple medications and conditions simultaneously. Clinical guidelines for stroke need to place greater emphasis on the management of multimorbidity, and further investigation of treatment burden in stroke is required to inform redesign of health services to improve patient outcomes.

\section{Additional files}

Additional file 1: Definitions of morbidities assessed.

Additional file 2: Stroke status in relation to demographic characteristics ( $n=1,424,378$ ).

Additional file 3: Stroke status and number of morbidities and repeat medications for two age groups.

Additional file 4: Stroke status and prevalence of physical morbidities ( $n=1,424,378$ ).

Additional file 5: Stroke status and prevalence of mental health morbidities ( $n=1,424,378)$.

\section{Abbreviations}

AF: Atrial fibrillation; CHD: Coronary heart disease; NHS: National Health Service; PCCIU: Primary Care Clinical Informatics Unit; QOF: Quality and Outcomes Framework

\section{Competing interests}

The authors declare that they have no competing interests.

Authors' contributions

$\mathrm{KIG}, \mathrm{GDB}, \mathrm{CRM}, \mathrm{PL}$ and FSM were involved in conception and design of this study. SM and BG designed the original study for which the data was

acquired, obtained the data and carried out the initial data management to define morbidities. $\mathrm{KIG}, \mathrm{GDB}, \mathrm{GMCL}$, and FSM were involved in data analysis. KIG, GDB, GMCL, SWM, BG and FSM interpreted the data. KIG drafted the manuscript which was revised by all other authors. All authors approved the final version. 


\section{Acknowledgements}

We thank the Chief Scientist Office of the Scottish Government Health Directorates (Applied Research Programme Grant ARPG/07/1); the Scottish School of Primary Care, which part-supported SWM's post and the development of the Applied Research Programme; and the Primary Care Clinical Informatics Unit at the University of Aberdeen, which provided the data. The views in this publication are not necessarily the views of the University of Aberdeen of University of Glasgow, their agents, or employees. We thank Katie Wilde and Fiona Chaloner of the University of Aberdeen, who performed the initial data extraction and management. GDB is a member of both the Alzheimer Scotland Dementia Research Centre funded by Alzheimer Scotland, and the University of Edinburgh Centre for Cognitive Ageing and Cognitive Epidemiology, and part of the cross-council Lifelong Health and Wellbeing Initiative (G0700704/ 84698). Funding from the BBSRC, EPSRC, ESRC, and MRC is gratefully acknowledged. We thank Jane Goodfellow for help with Figures 1 and 2. This study was funded by a CSO Clinical Academic Fellowship CAF/10/03 and the CSO 'Living Well with Multimorbidity' programme (ARPG/07/1). The funders had no role in study design, data collection and analysis, decision to publish, or preparation of the manuscript.

\section{Author details}

${ }^{1}$ Institute of Health and Wellbeing, University of Glasgow, Glasgow G12 9LX, Scotland. ${ }^{2}$ Department of Epidemiology and Public Health, University College London, London WC1E 6BT, England. ${ }^{3}$ University of Edinburgh, Centre for Cognitive Ageing and Cognitive Epidemiology, Edinburgh EH8 9JZ, Scotland. ${ }^{4}$ University of Dundee, School of Medicine, Dundee DD2 4BF, Scotland. ${ }^{5}$ University of Southampton, Faculty of Health Sciences, Southampton SO17 1BJ, England. ${ }^{6}$ Institute of Cardiovascular and Medical Sciences, University of Glasgow, Glasgow G4 OSF, Scotland.

Received: 24 April 2014 Accepted: 12 August 2014

Published online: 03 October 2014

\section{References}

1. Barnett K, Mercer SW, Norbury M, Watt G, Wyke S, Guthrie B: Epidemiology of multimorbidity and implications for health care, research, and medical education: a cross-sectional study. Lancet 2012, 380:37-43. doi:10.1016/S0140-6736(12)60240-2.

2. Valderas JM, Starfield B, Sibbald B, Salisbury C, Roland M: Defining comorbidity: implications for understanding health and health services. Ann Fam Med 2009, 7:357-363. doi:10.1370/afm.983.

3. May C, Montori VM, Mair FS: We need minimally disruptive medicine. BMJ 2009, 339:b2803.

4. Hughes LD, McMurdo MET, Guthrie B: Guidelines for people not for diseases: the challenges of applying UK clinical guidelines to people with multimorbidity. Age Ageing 2013, 42:62-69.

5. Eton DT, Ramalho-de Oliveira D, Egginton JS, Ridgeway JL, Odell L, May CR, Montori VM: Building a measurement framework of burden of treatment in complex patients with chronic conditions: a qualitative study. Patient Relat Outcome Meas 2012, 3:39-49.

6. Gallacher K, May C, Montori VM, Mair FS: Understanding treatment burden in chronic heart failure patients: a qualitative study. Ann Fam Med 2011, 9:235-243.

7. Tran VT, Montori VM, Eton DT, Baruch D, Falissard B, Ravaud P. Development and description of measurement properties of an instrument to assess treatment burden among patients with multiple chronic conditions. BMC Med 2012, 10:68.

8. Jani B, Blane D, Browne S, Montori VM, May CR, Shippee ND, Mair FS: Identifying treatment burden as an important concept for end of life care in those with advanced heart failure. Curr Opin Support Palliat Care 2013, 7:3-7. doi:10.1097/SPC.0b013e32835c071f.

9. Shippee ND, Shah ND, May CR, Mair FS, Montori VM: Cumulative complexity: a functional, patient-centered model of patient complexity can improve research and practice. J Clin Epidemiol 2012, 65:1041-1051. doi:10.1016/j.jclinepi.2012.05.005.

10. Vik SA, Maxwell CJ, Hogan DB: Measurement, correlates, and health outcomes of medication adherence among seniors. Ann Pharmacother 2004, 38:303-312. doi:312.10.1345/aph.1D252.

11. Eton DT, Elraiyah TA, Yost KJ, Ridgeway JL, Johnson A, Egginton JS, Mullan RJ, Murad MH, Erwin PJ, Montori VM: A systematic review of patient-reported measures of burden of treatment in three chronic diseases. Patient Relat Outcome Meas 2013, 4:7-20.

12. Calderon-Larranaga A, Poblador-Plou B, Gonzalez-Rubio F, Gimeno-Feliu LA, Abad-Diez JM, Prados-Torres A: Multimorbidity, polypharmacy, referrals, and adverse drug events: are we doing things well? Br J Gen Pract 2012, 62:e821-e826. doi:10.3399/bjgp12X659295.

13. Sehgal V, Bajwa SJ, Sehgal R, Bajaj A, Khaira U, Kresse V: Polypharmacy and potentially inappropriate medication use as the precipitating factor in readmissions to the hospital. J Fam Med Prim Care 2013, 2:194-199. doi:10.4103/2249-4863.117423.

14. Duerden M, Avery T, Payne R: Polypharmacy and Medicines Optimisation: Making It Safe and Sound. [http://www.kingsfund.org.uk/publications/ polypharmacy-and-medicines-optimisation]

15. Fulton MM, Riley Allen E: Polypharmacy in the elderly: a literature review. J Am Assoc Nurse Pract 2005, 17:123-132.

16. Hajjar ER, Cafiero AC, Hanlon JT: Polypharmacy in elderly patients. Am J Geriatr Pharmacother 2007, 5:345-351. doi:10.1016/j.amjopharm.2007.12.002.

17. Viktil KK, Blix HS, Moger TA, Reikvam A: Polypharmacy as commonly defined is an indicator of limited value in the assessment of drug-related problems. Br J Clin Pharmacol 2007, 63:187-195. doi:10.1111/j.1365-2125.2006.02744.X.

18. Avery AJ, Barber N, Ghaleb M, Franklin BD, Armstrong S, Crowe S, Dhillon S, Freyer A, Howard R, Pezzolesi C, Serumaga B, Swanwick G, Talabi O: Investigating the Prevalence and Causes of Prescribing Errors in General Practice: The PRACtICe Study. GMC Publication; 2012:1-5.

19. Payne RA, Avery AJ, Duerden M, Saunders $C L$, Simpson CR, Abel GA: Prevalence of polypharmacy in a Scottish primary care population. Eur J Clin Pharmacol 2014, doi:10.1007/s00228-013-1639-9.

20. Lehnert T, Heider D, Leicht H, Heinrich S, Corrieri S, Luppa M, Riedel-Heller S, Konig HH: Review: health care utilization and costs of elderly persons with multiple chronic conditions. Med Care Res Rev 2011, 68:387-420. doi:10.1177/1077558711399580

21. Taylor AW, Price K, Gill TK, Adams R, Pilkington R, Carrangis N, Shi Z, Wilson D: Multimorbidity - not just an older person's issue. Results from an Australian biomedical study. BMC Public Health 2010, 10:718. doi:10.1186/1471-2458-10-718.

22. Muggah E, Graves E, Bennett C, Manuel DG: The impact of multiple chronic diseases on ambulatory care use; a population based study in Ontario, Canada. BMC Health Serv Res 2012, 12:452. doi:10.1186/1472-6963-12-452.

23. Gallacher K, Morrison D, Jani B, Macdonald S, May CR, Montori VM, Erwin PJ, Batty GD, Eton DT, Langhorne P, Majeed A: Uncovering treatment burden as a key concept for stroke care: a systematic review of qualitative research. PLOS Med 2013, 10. doi:10.1371/journal.pmed.1001473.

24. Foley N, McClure JA, Meyer M, Salter K, Bureau Y, Teasell R: Inpatient rehabilitation following stroke: amount of therapy received and associations with functional recovery. Disabil Rehabil 2012, 34:2132-2138.

25. Chatterjee P, Cucchiara BL, Lazarciuc N, Shofer FS, Pines JM: Emergency department crowding and time to care in patients with acute stroke. Stroke 2011, 42:1074-1080.

26. O'Carroll R, Whittaker J, Hamilton B, Johnston M, Sudlow C, Dennis M: Predictors of adherence to secondary preventive medication in stroke patients. Ann Behav Med 2011, 41:383-390.

27. Ostwald SK, Wasserman J, Davis S: Medications, comorbidities, and medical complications in stroke survivors: The CAReS study. Rehabil Nurs 2006, 31:10-14.

28. Berlowitz DR, Hoenig H, Cowper DC, Duncan PW, Vogel WB: Impact of comorbidities on stroke rehabilitation outcomes: does the method matter? Arch Phys Med Rehabil 2009, 89:1903-1906.

29. Goldstein LB, Samsa GP, Matchar DB, Horner RD: Charlson Index comorbidity adjustment for ischaemic stroke outcome studies. Stroke 2004, 35:1941-1945.

30. van Baal $P$, Engelfriet $P$, Boshuizen $H$, van de Kassteele J, Schellevis $F$, Hoogenveen R: Co-occurrence of diabetes, myocardial infarction, stroke, and cancer: quantifying age patterns in the Dutch population using health survey data. Popul Health Metr 2011, 9:51. doi:10.1186/1478-7954-9-51.

31. Lui M, Domen $\mathrm{K}$, Chino N: Comorbidity measures for stroke outcome research: a preliminary study. Arch Phys Med Rehabil 1997, 78:166-172.

32. Information Services Division Scotland: Stroke statistics update; 2014. [http://www.isdscotland.org/Health-Topics/Stroke/Publications/2014-01-28/ 2014-01-28-Stroke-Report.pdf?65620058775]

33. Mizokami F, Koide Y, Noro T, Furuta K: Polypharmacy with common diseases in hospitalized elderly patients. Am J Geriatr Pharmacother 2012, 10:123-128. 
34. Schmidt M, Jacobsen JB, Johnsen SP, Botker HE, Sorensen HT: Eighteen-year trends in stroke mortality and the prognostic influence of comorbidity. Neurology 2014, 82:340-350. doi:10.1212/WNL.0000000000000062.

35. Zhu H, Hill MD: Stroke: the Elixhauser Index for comorbidity adjustment of in-hospital case fatality. Neurology 2008, 71:283-287. doi:10.1212/01. wnl.0000318278.41347.94

36. Johansen HL, Wielgosz AT, Nguyen K, Fry RN: Incidence, comorbidity, case fatality and readmission of hospitalized stroke patients in Canada. Can J Cardiol 2006, 22:65-71.

37. Elder R, Kirkpatrick M, Ramsay W, MacLeod M, Guthrie B, Sutton M, Watt G: Measuring Quality in Primary Medical Services Using Data from SPICE. Information and Statistics Division, NHS National Services Scotland; 2007.

38. Lis Y, Mann RD: The VAMP Research multi-purpose database in the UK. J Clin Epidemiol 1995, 48:431-443.

39. Carstairs V, Morris R: Deprivation and Health in Scotland. Aberdeen: Aberdeen University Press; 1991.

40. Diederichs C, Berger K, Bartels DB: The measurement of multiple chronic diseases-a systematic review on existing multimorbidity indices. J Gerontol A Biol Sci Med Sci 2011, 66:301-311. doi:10.1093/gerona/gla208.

41. Health and Social Care Information Centre: Quality and Outcomes Framework. [http://www.hscic.gov.uk/qof]

42. NHS Health Scotland: NHS Health Scotland. [http://www.healthscotland. com/resources/index.aspx]

43. Huntley AL, Johnson R, Purdy S, Valderas JM, Salisbury C: Measures of multimorbidity and morbidity burden for use in primary care and community settings: a systematic review and guide. Ann Fam Med 2012 10:134-141. doi:10.1370/afm.1363.

44. Go AS, Mozaffarian D, Roger VL, Benjamin EJ, Berry JD, Borden WB, Bravata DM, Dai S, Ford ES, Fox CS, Franco S, Fullerton HJ, Gillespie C, Hailpern SM, Heit JA, Howard VJ, Huffman MD, Kissela BM, Kittner SJ, Lackland DT, Lichtman JH, Lisabeth LD, Magid D, Marcus GM, Marelli A, Matchar DB, McGuire DK, Mohler ER, Moy CS, Mussolino ME, Nichol G, Paynter NP, Schreiner PJ, Sorlie PD, Stein J, Turan TN, Virani SS, Wong ND, Woo D, Turner MB: Heart disease and stroke statistics update: a report from the American Heart Association. Circulation 2013, 127:e6-e245.

45. National Institute for Health and Care Excellence (NICE): Stroke Rehabilitation: Long Term Rehabilitation After Stroke (CG162). NICE; 2013.

46. Gandhi TK, Weingart SN, Borus J, Seger AC, Peterson J, Burdick E, Seger DL, Shu K, Federico F, Leape LL, Bates DW: Adverse drug events in ambulatory care. N Engl J Med 2003, 348:1556-1564.

47. Calderón-Larrañaga A, Gimeno-Feliu LA, González-Rubio F, Poblador-Plou B, Lairla-San José M, Abad-Diez JM, Prados-Torres A: Polypharmacy patterns: unravelling systematic associations between prescribed medications. PLoS One 2013, 8:e84967.

48. May CR, Eton DT, Boehmer K, Gallacher K, Hunt KJ, MacDonald S, Mair FS, May CM, Montori VM, Richardson A, Rogers AE, Shippee N: Rethinking the patient: using Burden of Treatment Theory to understand the changing dynamics of illness. BMC Health Serv Res 2014, 14:281.

49. Wood JP, Connelly DM, Maly MR: "Holding me back": living with arthritis while recovering from stroke. Arch Phys Med Rehabil 2009, 90:494-500.

50. Moroney JT, Tseng CL, Paik MC, Mohr JP, Desmond DW: Treatment for the secondary prevention of stroke in older patients: the influence of dementia status. J Am Geriatr Soc 1999, 47:824-829.

51. Marcum ZA, Gellad WF: Medication adherence to multidrug regimens. Clin Geriatr Med 2012, 28:287-300. doi:10.1016/j.cger.2012.01.008.

52. Tinetti M, Fried TR, Boyd CM: Designing health care for the most common chronic condition-multimorbidity. JAMA 2012, 307:2493-2494.

53. U.S. Department of Health and Human Services: Multiple Chronic Conditions: A Strategic Framework Optimum Health and Quality of Life for Individuals with Multiple Chronic Conditions. U.S. Department of Health and Human Services; 2010.

54. Scottish Intercollegiate Guidelines Network: Management of Patients with Stroke: Rehabilitation, Prevention and Management of Complications, and Discharge Planning no 118. 2010. Available: http://www.sign.ac.uk/ guidelines/fulltext/118/index.html Accessed 6th February 2013.

55. Canadian Stroke Network and the Heart and Stroke Foundation of Canada: Canadian Best Practice Recommendations for Stroke Care. 2010. http://www. strokebestpractices.ca/.

56. Miller EL, Murray L, Richards L, Zorowitz RD, Bakas T, Clark P, Billinger SA, on behalf of the American Heart Association Council on Cardiovascular Nursing and the Stroke Council: Comprehensive overview of nursing and interdisciplinary rehabilitation care of the stroke patient: a scientific statement from the American Heart Association. Stroke 2010, 41:2402-2448.

57. United States Department of Veteran Affairs: Management of Stroke Rehabilitation. 2010. http://www.healthquality.va.gov/guidelines/Rehab/stroke/

58. Boyd CM, Darer J, Boult C, Fried LP, Boult L, Wu AW: Clinical practice guidelines and quality of care for older patients with multiple comorbid diseases: Implications for pay for performance. JAMA 2005, 294:716-724. doi:10.1001/jama.294.6.716.

59. Guthrie B, Payne K, Alderson P, McMurdo MET, Mercer SW: Adapting clinical guidelines to take account of multimorbidity. BMJ 2012, 345:e6341.

60. Stange KC: The generalist approach. Ann Fam Med 2009, 7:198-203.

61. Reeve J, Blakeman T, Freeman GK, Green LA, James PA, Lucassen P, Martin CM, Sturmberg JP, van Weel C: Generalist solutions to complex problems: generating practice-based evidence - the example of managing multi-morbidity. BMC Fam Pract 2013, 14:112.

62. Stroke Association: Stroke Statistics. 2013. http://www.stroke.org.uk/resourcesheet/stroke-statistics.

doi:10.1186/s12916-014-0151-0

Cite this article as: Gallacher et al:: Stroke, multimorbidity and polypharmacy in a nationally representative sample of 1,424,378 patients in Scotland: implications for treatment burden. BMC Medicine 2014 12:151.

\section{Submit your next manuscript to BioMed Central and take full advantage of:}

- Convenient online submission

- Thorough peer review

- No space constraints or color figure charges

- Immediate publication on acceptance

- Inclusion in PubMed, CAS, Scopus and Google Scholar

- Research which is freely available for redistribution 